\title{
Errata
}

eCAM 2005; 2(1): 13-18 doi:10.1093/ecam/neh068

\section{Lecture Series}

The Systemic Theory of Living Systems and Relevance to

\section{CAM}

Part I: The Theory

José A. Olalde Rangel

Adaptogenic Educational Medical Centers and Venezuelan Association of Systemic Medicine Caracas, Venezuela

The author would like to apologize for the incorrect reference 2 in this paper. The reference should be:

2. Selye H. The Stress in my Life: A scientist's memoirs. New York, NY: Van Nostrand Reinhold, 1979.

eCAM 2005; 2(3): 267-275 doi:10.1093/ecam/neh119

\section{The Systemic Theory of Living Systems and Relevance to CAM: the Theory (Part III)}

José A. Olalde Rangel

Adaptógenos Internacionales, Calle El Arenal c/c Luis de Camoes, La Trinidad, Caracas 1080, Venezuela
In the Introduction: The Need for a Biological Systems Theory, the first sentence reads as follows:

The function of the whole is tantemount to the individual action of its parts, due to synergy and emergence, inherent characteristics of all living systems (15).

However it should read as:

The function of the whole is greater to the individual action of its parts, due to synergy and emergence, inherent characteristics of all living systems (15).

The editor would like to apologize for this error.

The author would like to apologize for the incorrect placement of reference 15 in this paper.

Reference 15 was placed as follows on page 268:

Introduction : The Need for a Biological Systems Theory The function of the whole is tantemount to the individual action of its parts, due to synergy and emergence, inherent characteristics of all living systems (15).

However it should have been cited here on page 269: Systemic Theory complements the core concepts of 'far from equilibrium', 'self-organization', autopoiesis, homeokinesis (16) and dissipative structures by introducing the missing parameters of the life equation: Intelligence and Survival (15). 


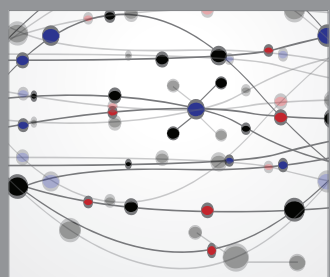

The Scientific World Journal
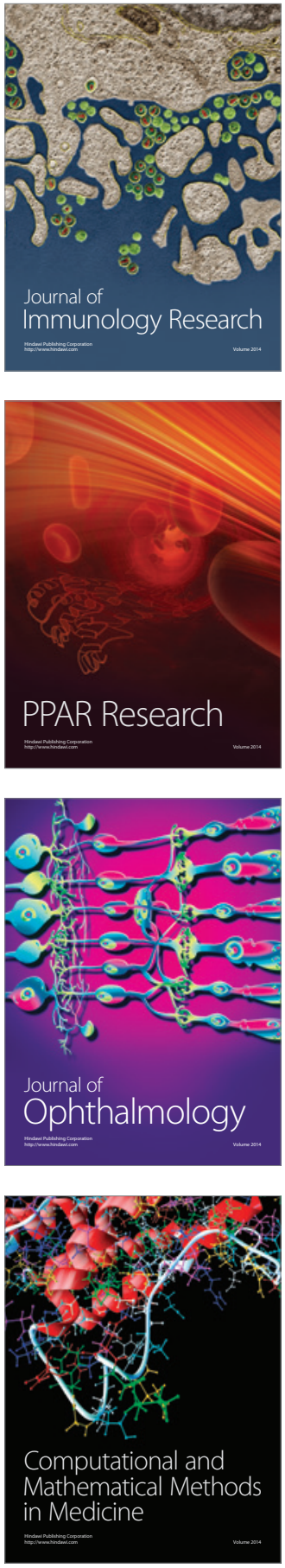

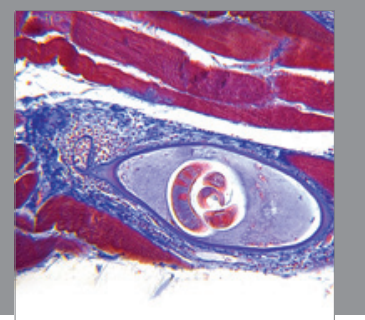

Gastroenterology

Research and Practice
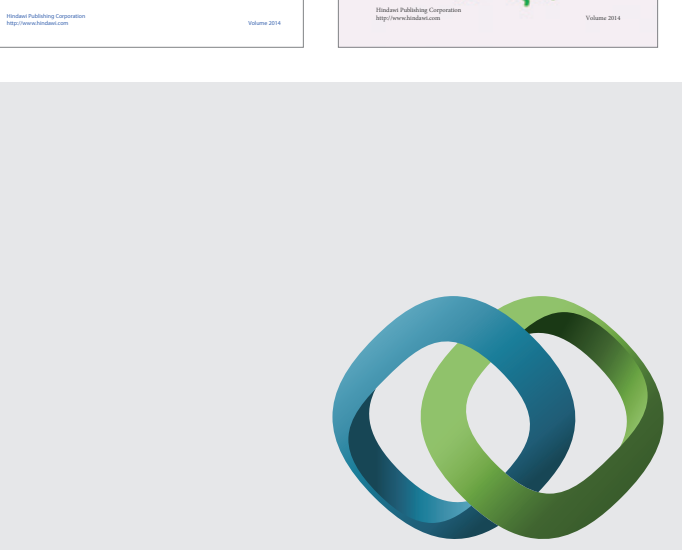

\section{Hindawi}

Submit your manuscripts at

http://www.hindawi.com
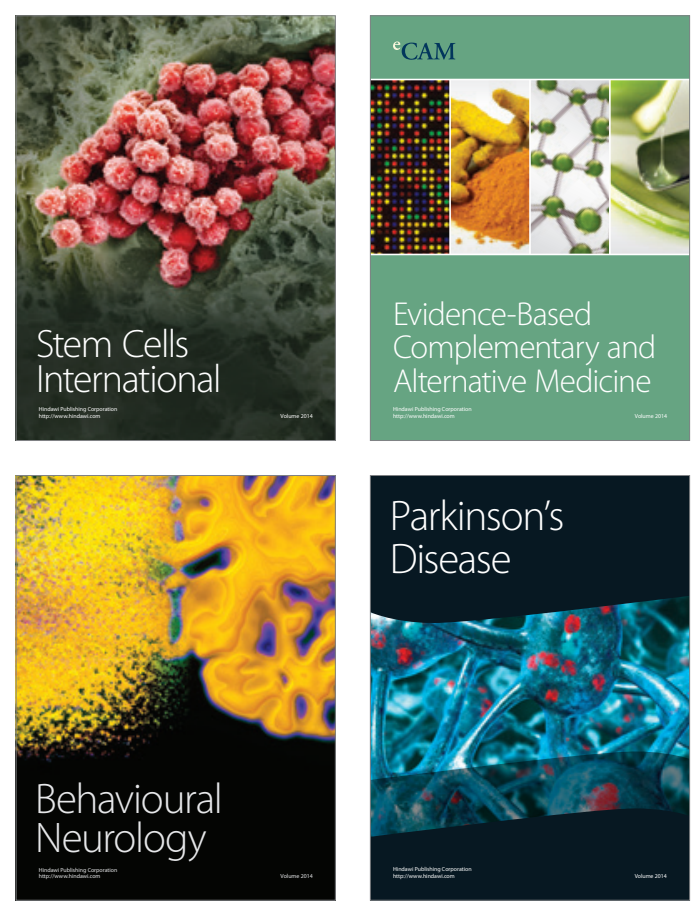

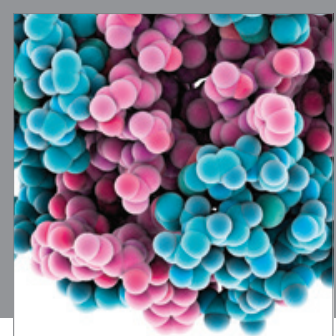

Journal of
Diabetes Research

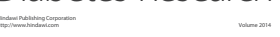

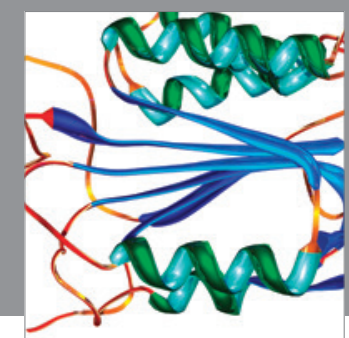

Disease Markers
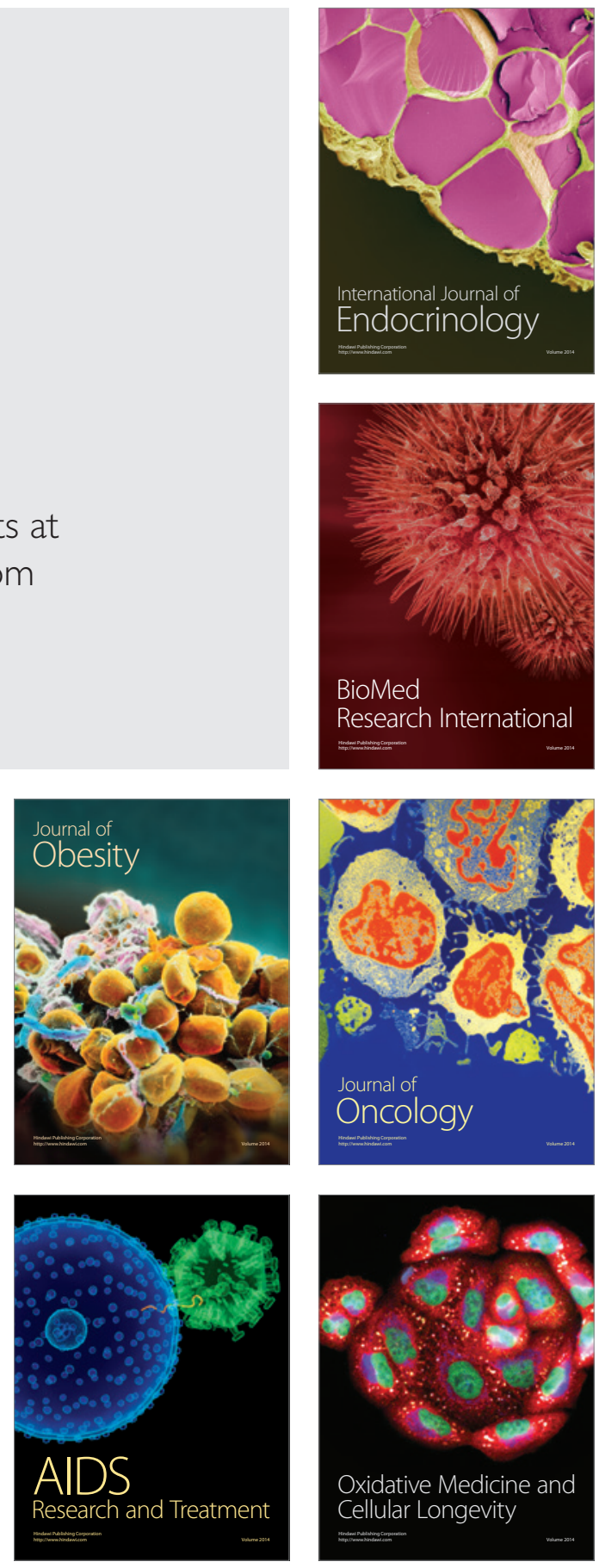